\title{
Journal of Education
}

\section{ISSN Online: 2616-8383}

Influence of Motivation on Academic Performance of Students in Germany

Zulnaidi Norhasnida Wilkesmann, Alfredo Steinmayr \& Khaizura Heike Fischer 


\title{
Influence of Motivation on Academic Performance of Students in Germany
}

\author{
${ }^{1 *}$ Zulnaidi Norhasnida Wilkesmann, ${ }^{2}$ Alfredo Steinmayr \& ${ }^{3}$ Khaizura Heike Fischer \\ ${ }^{1}$ Postgraduate student, University of Freiburg \\ ${ }^{2 \& 3}$ Lecturers, University of Freiburg
}

*Email of the corresponding author: norhasnidawilkesmann@gmail.com

\begin{abstract}
How to cite this article: Wilkesmann, Z., N, Steinmayr, A., \& Fischer, K., H. (2021). Influence of Motivation on Academic Performance of Students in Germany. Journal of Education 4 (6), 1-9. https://doi.org/10.53819/810181025018
\end{abstract}

\begin{abstract}
Motivation builds determination to achieve something. Motivated learners put in their maximum effort for achieving high academic performance in school. Thus, the study sought to examine the influence of motivation on the academic performance of students in Germany. The research adopted the cross-sectional research design. The target population was 374 teachers and students. The study did a sampling of 193 respondents that were selected from the target population of 374. Questionnaires were used to collect the data. The analysis of the data was done using descriptive and inferential statistics. The study results indicated that motivation is positively and significantly related to academic performance $(\beta=.243, \mathrm{p}=0.017)$. The results implied that when motivation improves by one unit, the academic performance among the students in Germany will increase by 0.243 units while other factors that influence the academic performance are held constant. The research concluded that sub-factors such as self-efficacy, active learning approaches and success goals have positive and considerable relationships with academic performance among the learners. The research suggested that the motivation of the students' needs to be fostered by teachers. The motivation of the students can maintain students' attention and behavior as well as provide with more energy to needed to lead tasks to completion. The study also recommended teachers need to encourage students, make learning fun, have one-on-one conversations and get parents involved in the students' learning process. It was also recommended that performing students be rewarded. The study further recommended that teachers need to give students as much control over their own education as possible and let them choose the topics that interest them in some cases.
\end{abstract}

Keywords: Motivation, Academic Performance, Students, Germany

https://doi.org/10.53819/810181025018 
Stratford Peer Reviewed Journals and Book Publishing

Journal of Education

Volume 4||Issue 6 ||Page 1-9 ||October |2021|

Email: info@stratfordjournals.org ISSN: 2616-8383

\subsection{Background of the Study}

Motivation is an intense desire or enthusiasm that enables an individual to attempt and do something to succeed (Saleh, 2019). It is a construct build-out of person understanding activities and experiences; it differs from one time to another. Motivation impacts learner understanding and plays an essential duty in guiding behavior toward a certain objective, increasing the effort and power in the direction of an objective, enhancing the initiative and perseverance of a task, and enhancing one's efficiency. Motivation is vital issue in maintaining learners in their schooling process, and was discovered to be main substantial aspect that influences learning performance. An inspired learner will look after his education and learning, have positive reasoning and is constantly anxious to study (Norhasnida, 2018). Teaching will be of no significance if the learner is not motivated, even where the capacity and capability of educators are good enough. Selfmotivation is vital to produce a possibility for excellence and is connected with the spirit and wishes to perform, and having a good influence on one's performance and achievement.

Motivation can be specified as the requirement or need connected to the will to fulfill an expected objective, or as the actions managed by the need and reaction to achieve a specific result. According to Garcia and Pintrich (2018) from the learning point of view, the motivation to carry out a task can be promoted by 3 elements: a reason or objective to do it; the person's idea in their capacity to execute it; and the affective responses gotten with the performance of the task. Two sorts of motivation can be identified: the inherent motivation, in which something is done for the interest and fulfillment inherent to the activity, and extrinsic motivation, in which something is done due to a various repercussions or outcome of the action. Motivation is a positioning in the direction of learning. As a result, it influences just how likely a learner is neither to surrender nor move forward, exactly how thoughtful their reflection on their studying will certainly be. The much higher the motivation for going after a task, the more probable that the learner will decline easy solution to intricate questions (Lepper, 2018). In other words, inherent motivation cultivates good and resilient critical reasoning abilities. Motivation and totally external motivation steer to reduce passion and schooling perseverance.

Learners who are fundamentally motivated take learning as a play. Most of the learners turn the learning process on their brain and view it from a different perspective. Motivated learners are not extra smart compared to unmotivated learners, yet their demand to get response to a particular assignment or to understand an idea leads to higher reasoning abilities (Ahmadova, 2020). Intrinsically motivated learners would reason about concerns past the boundaries of the class, due to fact that the existence of the instructor or the worry of a small quality is not the underlying factors for their reasoning. For that reason, motivated learners, through assuming longer and tougher and delighting in the obstacle of being puzzled, will certainly ask much deeper, much more provocative inquiries. Motivated learners are a lot more able to adjust out content to brand-new circumstances due to the fact that they have a tendency to reflect on underlying causes or structures (Wlodkowski \& Ginsberg, 2020).

Germany is a nation with many races and numerous societal backgrounds. Researches concerning elements impacting the academic attainment tend to concentrate on learners' motivational aspects from different learning institution and areas (Noor, 2020). A lot of researches concentrated a lot more on learners in the majority of Germany population, not the ethnic minority. The research of learner motivation among the minority group like aboriginal/indigenous learners is additionally

https://doi.org/10.53819/810181025018 
Stratford Peer Reviewed Journals and Book Publishing

Journal of Education

Volume 4||Issue 6 ||Page 1-9 ||October |2021|

Email: info@stratfordjournals.org ISSN: 2616-8383

essential as their growth may add to the education and learning advancement in Germany. Although indigenous individuals compose just a little percentage of the German population, they are overmuch influenced by hardship (Patrinos \& Psacharopoulos, 2018). The majority still survive on the edges of German culture, are removed from many social services, are poorly educated, and make an inadequate living. There is no selection among students of various history; therefore, there is no clue to see how learners from various places of culture show the connection of motivation and educational achievement.

The partnership of motivation and learning achievement is no question a fundamental section in the growth of learning (Peng, 2020). Students' motivation has been extensively approved as an important aspect that impacts the level and success of learning. Motivation is a vital factor for learners to attain good performance in any learning institution. Learners who are not motivated commonly face academic problems in classrooms (Wilkesmann \& Lio, 2019). As a result, one of the most vital duties for teachers is to foster learners' motivation to find out. Learners' motivation was considered an essential component to consider mentor and learning procedure at all stages of learning. Motivated learners will delight in learning both in and out of the class (Komarraju, Musulkin \& Bhattacharya, 2020). These learners trust in their capability to discover and will take responsibility for their learning. Hence, teachers should commit carefully to helping learners relate to different ideas. This can be done by clarifying the significance of scientific proficiency and its connection to job chances. Motivation is a vital issue in maintaining learners in their schooling process and was discovered to be the main substantial aspect that influences learning performance. An inspired learner will look after his education and learning, have positive reasoning and is constantly anxious to study. Motivation needs to be used in schools to attract more students and bring about competition among the students to perform well. This study aimed at determining the influence of motivation on the academic performance of students in Germany.

\subsection{Research Objective}

The objective of the study was to examine the influence of motivation on academic performance of students in Germany

\subsection{Literature Review}

Norhasnida (2018) researched the relationship between motivation and academic achievement among students in Germany. The results of the study showed that motivation is positively related to academic achievement. Motivation impacts learner understanding and plays a critical role in guiding behavior toward a certain objective, increasing the effort and power in the direction of an objective, enhancing the initiative and perseverance of a task, and enhancing one's efficiency. Motivation is vital issue in maintaining learners in their schooling process, and was discovered to be main substantial aspect that influences learning performance. Moreover, Patrinos and Psacharopoulos (2018) carried out a study to determine the degree of German learners' motivation with regards to the learning of Physics at the high school level, and its impacting aspects. The research was studied out on 337 Type 4 trainees who took Physics as a subject, from 6 institutions in Munich.

The study results showed that motivation plays a critical role in determining the learning of physics. Motivated students were very hardworking. Peng (2020) carried out research to determine the correlation between motivation, experience and the degree of satisfaction among completely

https://doi.org/10.53819/810181025018 
Stratford Peer Reviewed Journals and Book Publishing

Journal of Education

Volume 4||Issue 6 ||Page 1-9 ||October||2021|

Email: info@stratfordjournals.org ISSN: 2616-8383

online adult students in open distance learning schools. These attributes are frequently studied differently to analyze the degree of its impact on the grown-up internet students; however, occasionally looked at as one in research. A survey was performed to grown-up students who are presently pursuing Bachelor of human resource and tourist administration training majors that are completely online. An organized set of questions survey was made use of in information collection making use of Google Drive as the platform to disperse. On the whole, 69 online trainees completed the survey. Research from this perspective reveals that students are extremely encouraged with the principle of online understanding mostly concurring that completely on the internet programs permits them succeed in course offering if the materials are studied suitably. Nonetheless, their exposure and fulfillment with the totally on the internet system does not conform to the high degree of motivation. Leading aspects to the discontentment would certainly be the boundary of individual interaction and reliance on very own self-discipline. Participants revealed ordinary degree of complete satisfaction with the completely on the internet training courses. Nevertheless, adaptability of area and period given by totally online learning continue to be the leading logic for contentment. The ramification of these discovering discusses how teachers and training course formulators supply needed technical assistance to completely online students in handling their degree of motivation and contentment.

Tsymbal (2018) argued that motivation is among the essential factors in studying a language, the sensations and enjoyment provided by additional enthusiasm for learners to discover a second language in a much better means. This research investigated the aspects which will lead to motivation in learning English among 80 trainees of Sekolah Menengah Kebangsaan Lepar Utara. The tool of the research was a questionnaire. Findings for showed that educators affect, individual mindset and parental impact do have influence in impacting learners' motivation to discover a second language. Zee, Koomen and Van der Veen (2019) conducted a qualitative research to check out the connection between student-teacher relationship and learners' academic motivation. Two16-year old male pupils from a public boarding institution in the Peninsular of Malaysia were picked as respondents. Information was collected from two disorganized interviews. 5 themes within the learner-teacher connection were noticed throughout the interviews: care, support, trust fund, friendly and assumption. The discoveries for recommend that academic motivation is fostered when instructors show true treatment concerning the learners, give continuous assistance to the learners, build trust in the relationship, be social to the learners, and moderately high expectation in the direction of learners' accomplishment.

Tanduklangi and Lio (2019) conducted research to analyze the effect of mindset and motivation on pupils' English fundamental expertise at Senior high school Schools in Kendari City, Indonesia. The population of this study was all pupils of state secondary schools in Kendari city. Research variables consist of exogenous variables, particularly attitude and motivation of trainees; the endogenous variables are students' English basic knowledge. The sampling approach uses in proportion stratified random sampling. Data was accumulated by making use of questionnaire and observation. Measurement of study indicators using ordinal range with Likert range strategy. Data were analyzed descriptively to describe the tendency of participants in the form of classification, while inferential course analysis using SPSS 22 version to see the solid influence in between variables. The result reveals that motivation has a positive and considerable effect on performance.

https://doi.org/10.53819/810181025018 
Chetri (2017) performed research to determine the influence of motivation on the performance of students. The research was constrained to 480 senior high school leavers examining various institutions of Sikkim by utilizing stratified random sampling approaches from different government and non-government took care of institutions within the age variety of 16-17 years, from metropolitan and rural locations. The study noted that motivation is a vital issue in maintaining learners' schooling process and is the foremost important aspect that influences learning performance. The study recommended that motivation be used in schools to attract more students and bring about competition among the students to perform well.

\subsection{Research Methodology}

The research adopted the cross-sectional research design. The target population was 374 teachers and students. The study did a sampling of 193 respondents that were selected from the target population of 374. Questionnaires were used to collect the data. The analysis of the data was done using descriptive and inferential statistics.

\subsection{Research Findings and Discussion}

\subsection{Correlation analysis}

The correlation analysis was done to examine the association between variables. The study results of the correlation analysis is presented in Table 1

Table 1: Correlation Analysis

Academic performance Motivation

Academic performance Pearson Correlation 1.000

Sig. (2-tailed)

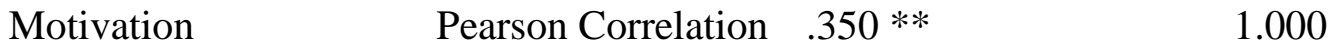

$\begin{array}{lll}\text { Sig. (2-tailed) } \quad 0.000 & 0.000\end{array}$

The correlation results presented in Table 1 show that motivation is positively and significantly associated with academic performance $(\mathrm{r}=.350, \mathrm{p}=.000)$. This implied an improvement in the motivation leads to an enhancement of the academic performance among the students in Genabnt. The results concur with Drwish (2018), who revealed that there is a relationship between motivation and academic achievement. Peng, (2020) exposed that motivated learner is more performing that those students who are not motivated. Further, Norhasnida (2018) showed that motivation is positively related to academic achievement. Motivation impacts learner understanding and plays a critical role in guiding behavior toward a certain objective, increasing the effort and power in the direction of an ideal, enhancing the initiative and perseverance of a task, and enhancing one's efficiency. Motivation is a vital issue in maintaining learners' schooling process and the principal aspect influencing learning performance. Chetri (2017) noted that motivation is an essential issue in maintaining learners' schooling process and is the foremost important aspect that affects learning performance. The study recommended that motivation be 
used in schools to attract more students and bring about competition among the students to perform well.

\subsection{Regression Analysis}

The section comprised of model fitness, analysis of variance and regression of coefficient. The results presented in Table 2 indicate the model fitness.

Table 2: Model Fitness

\begin{tabular}{lllll}
\hline Model & $\mathrm{R}$ & R Square & Adjusted R Square & Std. Error of the Estimate \\
\hline 1 & $.156 \mathrm{a}$ & 0.328 & 0.321 & 0.143038
\end{tabular}

The result from Table 2 shows that motivation was found to be satisfactory in explaining the academic performance among the students in Germany. This was supported by the coefficient of determination, also known as the $\mathrm{R}$ square of 0.328 . This implied that motivation explains $32.8 \%$ of the variations in the academic performance among the students in Germany.

Table 3: Analysis of Variance

\begin{tabular}{lllllll}
\hline Model & & Sum of Squares & df & Mean Square & F & Sig. \\
\hline 1 & Regression & 3.154 & 4 & 2.578 & 21.66 & $.000 \mathrm{~b}$ \\
& Residual & 4.561 & 6 & 0.119 & & \\
& Total & 7.715 & 10 & & & \\
\hline
\end{tabular}

The results in Table 3 indicate that the overall model was statistically significant. The results imply that motivation is a good predictor in explaining the academic performance among the students in Germany. This was supported by an F statistic of 21.66 and the reported p-value of 0.000 , which was less than the conventional probability significance level of 0.05 . Therefore, the schools can work on improving the motivation strategies to increase the academic performance of students in Germany.

Table 4: Regression of Coefficient

\begin{tabular}{|c|c|c|c|c|c|}
\hline & \multicolumn{2}{|c|}{ Unstandardized Coefficients } & Standardized Coefficients & $\mathrm{t}$ & Sig. \\
\hline & B & Std. Error & Beta & & \\
\hline (Constant) & 0.249 & 0.046 & & 5.413. & 0.024 \\
\hline Motivation & 0.243 & 0.095 & 0.291 & 2.558 & 0.017 \\
\hline
\end{tabular}

Based on the results presented in Table 4, it was found that motivation is positively and significantly related to academic performance $(\beta=.243, \mathrm{p}=0.017)$. The results implied that when 
Stratford Peer Reviewed Journals and Book Publishing

Journal of Education

Volume 4||Issue 6 ||Page 1-9 ||October |2021|

Email: info@stratfordjournals.org ISSN: 2616-8383

motivation improves by one unit, the academic performance among the students in Germany will increase by 0.243 units while other factors that influence the academic performance are held constant. When students are motivated, they tend to perform well in their studies. Motivation needs to be used in schools in order to attract more students to school and bring about competition among the students so that they can perform well. The teachers are required to come up with new strategies to motivate students. The results agree with Yahaya, Yahaya, Ramli, Hashim \& Zakariya (2018), who found that Malaysian students' motivation was positively and significantly related with academic performance. Further, Norhasnida (2018) showed that motivation is positively related to academic achievement. Motivation impacts learner understanding and plays a critical role in guiding behavior toward a certain objective, increasing the effort and power in the direction of an ideal, enhancing the initiative and perseverance of a task, and enhancing one's efficiency. Motivation is a vital issue in maintaining learners' schooling process and the principal aspect influencing learning performance. Chetri (2017) noted that motivation is an essential issue in maintaining learners' schooling process and is the foremost important aspect that affects learning performance. The study recommended that motivation be used in schools to attract more students and bring about competition among the students to perform well. Khalaila (2019) demonstrated the relationship between motivation and academic achievement is positive.

\subsection{Conclusion and Recommendations}

The study concluded that motivation improves academic performance. Motivation has a positive and considerable impact on the academic performance of the students. The research concluded that sub-factors such as self-efficacy, active learning approaches and success goals have positive and considerable relationships with academic performance among the learners. Furthermore, the study concluded that motivated learners are able to adjust out content to new circumstances due to the fact that they have a tendency to reflect on underlying causes or structures and motivated learners will delight in learning both in and out of the class. The research suggested that the motivation of the students need to be fostered by teachers. The motivation of the students can maintain students' attention and behavior as well as provide with more energy to needed to lead tasks to completion. The motivation of students can have a variety of effects on students' behavior, preferences, and results. The study also recommended teachers need to encourage students, make learning fun, have one-on-one conversations, and get parents involved in the students' learning process. It is also recommended that performing students be rewarded. The study further recommended that teachers need to give students as much control over their own education as possible and let them choose the topics that interest them in some cases. 


\section{REFERENCES}

Ahmadova, T. (2020). The Role of Motivation in Teaching and Learning Process. Journal of Education (42-2), 41-42.

Chetri, S. (2017). Achievement motivation of adolescents and its relationship with academic achievement. International Journal of Humanities and Social Science Invention, 3(6), 815.

Drwish, S. A. (2018). Instrumental and integrative motivation to learn English among students at Centre for Language and Pre-University Academic Development (CELPAD), International Islamic University Malaysia (IIUM) (Master's thesis, Kuala Lumpur: International Islamic University Malaysia, 2018).

Garcia, T., \& Pintrich, P. R. (2018). Assessing students' motivation and learning strategies in the classroom context: The Motivated Strategies for Learning Questionnaire. In Alternatives in assessment of achievements, learning processes and prior knowledge (pp. 319-339). Springer, Dordrecht. https://doi.org/10.1007/978-94-011-0657-3_12

Khalaila, R. (2019). The relationship between academic self-concept, intrinsic motivation, test anxiety, and academic achievement among nursing students: Mediating and moderating effects. Nurse Education Today, 35(3), 432-438. https://doi.org/10.1016/j.nedt.2014.11.001

Komarraju, M., Musulkin, S., \& Bhattacharya, G. (2020). Role of student-faculty interactions in developing college students' academic self-concept, motivation, and achievement. Journal of college student development, 51(3), 332-342. https://doi.org/10.1353/csd.0.0137

Lepper, M. R. (2018). Motivational considerations in the study of instruction. Cognition and instruction, 5(4), 289-309. https://doi.org/10.1207/s1532690xci0504_3

Nauzeer, S., \& Jaunky, V. C. (2019). Motivation and academic performance: A SEM approach. International Journal of Environmental and Science Education, 14(1), 41-60.

Noor, I. H. (2020). The Relationship between Intrinsic Motivation and Academic Performance among Non-Business Students Enrolling Entrepreneurship Course in Germany. Journal of Education, 4(2), 17-26

Norhasnida, Z. M., (2018). Learning support and academic achievement among Germany adolescents: The mediating role of student engagement. Learning Environments Research, 19(2), 221-240. https://doi.org/10.1007/s10984-015-9202-5

Patrinos, H. A., \& Psacharopoulos, G. (2018). Family size, schooling and child labor in Peru-An empirical analysis. Journal of population economics, 10(4), 387-405. https://doi.org/10.1007/s001480050050

Peng, Y. (2020). Quality teachers and students' motivation: how to make students eager to learn in Germany. International Journal of Education 3(7), 17-31 
Saleh, S. (2019). Malaysian Students' Motivation towards Physics Learning. European Journal of Science and Mathematics Education, 2(4), 223-232. https://doi.org/10.30935/scimath/9414

Tsymbal, S. (2018). Gamified Training Sessions As Means Of Enhancing Students'motivation In Learning English. Psychological Journal, 4(7), 151-161. https://doi.org/10.31108/1.2018.7.17.10

Wilkesmann, A., \& Lio, A. (2019). Classroom Action Research in Teaching English for Senior High School Students through Blended Learning in Germany. Journal of e-Learning and Knowledge Society, 15(1), 18-23

Wlodkowski, R. J., \& Ginsberg, M. B. (2020). Enhancing adult motivation to learn: A comprehensive guide for teaching all adults. John Wiley \& Sons.

Zee, M., Koomen, H. M., \& Van der Veen, I. (2019). Student-teacher relationship quality and academic adjustment in upper elementary school: The role of student personality. Journal of School psychology, 51(4), 517-533. https://doi.org/10.1016/j.jsp.2013.05.003

Zulnaidi S., \& Fischer, Y. (2020). The effects of extrinsic motivational factors in learning among students in secondary school in Germany. International Journal of Psychological Studies, 2(1), 128. https://doi.org/10.5539/ijps.v2n1p128 